\title{
Tempo e espaço na forma shandiana: Sterne e M achado de Assis
}

SER Gio PAulo R OUANET

\section{A forma shandiana}

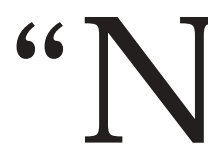

Ão consu LTES dicionários": foi assim que Bentinho chamou atenção, em D om C asmur ro, para o uso especial que el e fazia da palavra casmurro, diferente do que aparecia nos dicionários de língua portuguesa ${ }^{1}$. Do mesmo modo, recomendo que não consultem os dicionários de inglês para entenderem o título deste artigo. A palavra shandean, no Webster's International Dictionary, significa "one who has the spirit of Tristram Shandy", e shandysm é definido como "the philosophy of Tristram Shandy". Para essa acepção, o shandismo é uma atitude diante da vida, uma concepção do mundo, um modo de enfrentar a vida e seus absurdos. Esse uso é atestado pelo próprio Sterne. "True shandysm", diz ele, "opens the hearts and lungs, forces the blood and other vital fluids of the body to rum freely through its channels, makes the wheel of life run long and cheerfully round" 2 . A palavra tem às vezes um conteúdo um tanto repreensível, como quando Sterne afirma, virtuosamente, ser menos shandiano do que as pessoas acreditam. Ela designa uma atitude entre libertina e sentimental, um sensualismo risonho, um humor afável e tolerante, capaz de perdoar transgressões próprias e alheias, mas também de zombar, sem excessiva malícia, dos grandes e pequenos ridículos do mundo. N essa significação, 0 shandismo é uma maneira de ver e sentir, no fundo, uma questão de temperamento, e, nesse sentido, podemos falar em personalidades shandianas, sem pensarmos em Sterne, do mesmo modo que aludimos a personalidades pantagruélicas ou quixotescas, sem em nenhum momento pensarmos nem em Rabelais nem em Cervantes.

Em vez disso, proponho usar o termo para designar uma forma literária a forma shandiana. Em que consiste ela? Paradoxalmente, não é em Sterne que buscaremos uma resposta, e sim num dos mais perfeitos cultores da forma shandiana, nascido 126 anos depois de Sterne e a muitos milhares de quilômetros de sua I rlanda natal: M achado de Assis.

A resposta está nas primeiras páginas de $M$ emórias póstumasde Brás $C$ ubas. Releiamos o prefácio ao leitor, de Brás Cubas: 
Trata-se, na verdade, de uma obra difusa, na qual eu, B rás Cubas, se adotei a forma livre de um Sterne ou de um Xavier de $M$ aistre, não sei se Ihe meti al gumas rabugens de pessimismo. Pode ser. Escrevi-a com a pena da galhofa e a tinta da melancolia, e não é difícil antever o que poderá sair desse conúbio.

No prólogo à terceira edição, o próprio M achado de Assis toma a palavra, acrescentando um terceiro nome, o de Almeida Garrett, e dizendo que toda aquela gente tinha viajado: "Xavier de M aistre à roda do quarto, G arrett na terra dele, Sterne na terra dos outros. D e B rás C ubas se pode dizer que viajou à roda da vida". Enfim, no capítulo I, o narrador chama atenção para as liberdades tomadas com a cronologia: em vez de contar em primeiro lugar seu nascimento, começa com a narração de sua morte 3 .

$\mathrm{N}$ essas linhas, $\mathrm{M}$ achado delimita uma família intelectual, composta de todos os autores que aderiram a uma certa "forma": Sterne, patriarca da família, dois dos seus "descendentes", Xavier de M aistre e A Imeida G arrett, e a ele próprio. E vai mais além: dá contornos conceituais a essa forma. É uma forma caracterizada 1) pela presença constante e caprichosa do narrador, ilustrada enfaticamente pelo pronome de primeira pessoa: “Eu, Brás Cubas ; 2) por uma técnica de composição difusa e livre, isto é, digressiva, fragmentária, não-discursiva; 3) pela interpenetração do riso e da melancolia; e 4) pela subjetivação radical do tempo (os paradoxos da cronologia) e do espaço (as viagens).

$M$ achado de Assis definiu exaustivamente essa forma, mas não a nomeou. Para preencher esse déficit terminológico, decidi usar o adjetivo "shandiano", para deixar claro que a origem da forma está no romance de L aurence Sterne, Tristram Shandy. N ão estou querendo dizer com isso que Sterne não tenha tido antecedentes, porque depois que J osé Guilherme M erquior escreveu um ensaio pioneiro em que enquadrava $M$ achado de Assis na tradição da sátira menipéia ${ }^{4}$, ninguém tem o direito de ignorar que Sterne é herdeiro dessa tradição, que se iniciou no século III a.C. com o filósofo cínico M enipo de Gandara, prosseguiu, na Antigüidade, com Varrão, Sêneca e Luciano de Samósata, e continuou, na Renascença e no Barroco, com Erasmo de Rotterdam e Robert Burton, antes de chegar, no século XVIII, ao autor de Tristram Shandy. M as não me parece que Sterne possa ser incluído, sem maiores mediações, no veio central da tradição menipéia, porque esta, tanto em sua maneira clássica quanto na renascentista, aplicava-se essencialmente à sátira, à comédia, ao diálogo filosófico, enquanto Sterne extraiu da literatura menipéia uma forma aplicável especificamente ao romance. A forma shandiana é a refuncionalização romanesca da tradição menipéia. A esse título, podemos dizer que Sterne inaugurou efetivamente uma forma, e que embora M achado conhecesse muito bem autores como Luciano e E rasmo, foi à forma shandiana, e não de modo imediato à literatura menipéia, que $M$ achado de Assis se filiou em M emórias póstumas.

U m estudo completo da forma shandiana teria que abranger, além do próprio $\mathrm{M}$ achado, os três outros autores mencionados em M emóriaspóstumas(Sterne, 
Xavier de M aistre e Almeida Garrett), e se possível outros, que M achado citou em várias passagens mas não incluiu na "família", como D iderot, cujo J acquesle fatalisteé um livro shandiano exemplar. E teria que examinar, em cada um desses autores, em suas semelhanças e diferenças, o funcionamento das quatro características estruturais da forma shandiana: a hipertro fia da subjetividade, a digressividade e a fragmentação, a mistura de riso e melancolia, e a subjetivação do tempo e do espaço.

Tratar de tudo isso nos limites de um artigo é obviamente impossível, e por isso serei duplamente seletivo, restringindo-me aqui a apenas dois autores, Sterne (Tristram Shandy) e M achado ( $M$ emórias póstumas de Brás $C$ ubas) ${ }^{5}$ e concentrando-me somente na última característica estrutural da forma shandiana (a subjetivação do tempo e do espaço).

\section{Tempo e espaço em Tristram Shandy}

Em Tristram Shandy, há uma profunda assimetria entre o tempo da ação e o tempo narrativo: em vez de reproduzir o tempo da ação, o tempo da narrativa o violenta. I ronicamente, Sterne cria a impressão de que é o tempo da ação que impõe seu ritmo ao tempo narrativo. Este passa a funcionar como a mímese daquele. Conseqüentemente, cada minuto da ação que está sendo narrada deve ocupar um minuto do tempo textual, seja na escrita, seja na leitura. C ada dia de trabalho do memorialista deveria ser capaz de abarcar um dia da vida de Tristram. U $\mathrm{m}$ trecho que pode ser lido em uma hora deve descrever um episódio que, de fato, teve a duração de uma hora. M as essa regra auto-imposta de correspondência temporal é evidentemente absurda, e Tristram expõe comicamente os seus numerosos fracassos. Assim, passam-se apenas dois minutos, treze segundos e três quintos entre o momento em que Walter tocara a campanhia, mandando o criado $\mathrm{O}$ badiah chamar o $\mathrm{Dr}$. Slop, e o momento em que $\mathrm{O}$ badiah bate na porta, trazendo consigo o médico. Segundo seu método, o narrador deveria ter entremeado entre os dois momentos materiais que pudessem ser lidos em dois minutos, treze segundos e três quintos. Em vez disso, ele é obrigado a reconhecer, diante das objeções de um imaginário "hiper-crítico", ter violado a lei da verossimilhança temporal, intercalando passagens que exigem no mínimo uma hora e meia de leitura ${ }^{6}$. Para seu desespero, ele verifica que estava trabal hando há seis semanas, e ainda não tinha nascido ${ }^{7}$. Suas perplexidades chegam ao clímax quando se dá conta de que já tinham se passado doze meses desde que começara a escrever, e não terminara ainda o relato do seu primeiro dia de vida. Em conseqüência, tinha mais 364 dias de vida a descrever que um ano atrás, de modo que em vez de progredir em sua tarefa com a passagem do tempo, atrasava-se à medida que a tarefa prosseguia. A tarefa é, portanto, propriamente interminável, já que cada dia de sua vida deveria ser descrito de modo tão exaustivo como o do seu nascimento. "At this ratel should live 364 times faster than I should write - it should follow, an' please your worships, that the more I write, the more I shall have to write" ${ }^{8}$. 
Tendo demostrado pela reductio ad absurdum a impossibilidade de imitar em sua narrativa o tempo da ação, T ristram deixa claro que a hegemonia pertence ao tempo narrativo. É este que comanda o jogo. 0 tempo narrativo captura em sua teia, como um inseto, o tempo da ação, e o dobra a seu jugo. 0 tempo narrativo, como no episódio da viagem de 0 badiah à procura do médico, pode ser mais longo que o tempo da ação, que durou pouco mais de dois minutos. $\mathrm{E}$ pode ser mais curto, porque durante essa hora e meia o narrador teve tempo de trazer Toby, ferido em $\mathrm{N}$ amur, até a Inglaterra, de mantê-lo inválido na casa de Walter Shandy, em L ondres, durante quatro anos, e de fazê-lo viajar, com Trim, até Yorkshire, para consagrar-se a seu hobby horse ${ }^{9}$.

O ra, como quem determina os ritmos do tempo narrativo é o próprio narrador, segue-se que é este o verdadeiro senhor do tempo. 0 narrador sentese autorizado a dispor sobre o tempo, porque declarou com todas as letras que não se considerava sujeito a regra alguma - nem às de Boileau, autor da regra da unidade do tempo, nem, muito menos, às de H orácio. "I should beg M r. H orace's pardon - for in writing what have set about, I shall confine myself neither to his rules nor to any man's rules that ever lived"10. E sente-se autorizado, também, pela própria ciência: a psicologia de L ocke, cujo conceito de tempo Walter explica a seu irmão Toby, quando M rs. Shandy estava dando à luz. Para Locke, o tempo é uma idéia, uma idéia de duração, obtida pela reflexão sobre a seqüência de nossas idéias. 0 conceito de sucessão surge quando refletimos sobre o aparecimento de várias idéias consecutivas; e a distância entre quaisquer partes dessa sucessão, ou o aparecimento de duas idéias em nossa mente, é o que chamamos duração. A duração é pois puramente subjetiva, e por isso o tempo pode passar lenta ou rapidamente, conforme nosso estado de espírito.

Como narrador, Tristram opera no eixo da duração e não do tempo quantitativo. É a sucessão das idéias do narrador que determina as articulações temporais do livro. Legitimado por L ocke, Tristram pode ser tão shandiano quanto quiser. Ele trata o tempo como tratou o leitor. Tristram depende do leitor para existir mas o maltrata; é vítima do tempo, porque o tempo é a morte que rói os seus pulmões, mas o desafia. A desenvoltura do narrador é a mesma. Se ele se diverte com o leitor, diverte-se também com o tempo, forçando-o a dar cambaIhotas e saltos mortais. Através do tempo narrativo, ele age a seu bel-prazer sobre o tempo da ação.

Q ual o tempo da ação, em Tristram Shandy? $N$ ada mais fácil de reconstituir. Ferido em N amur em 1695, Toby se instala em Londres, em casa do irmão, em julho de 1697, onde permanece em estado de invalidez até o início de 1701. Parte nesse ano para Yorkshire, em companhia de Trim, para dedicar-se a seu hobby horse. Prossegue em suas atividades marciais até a paz de U trecht, em 1713, atividades só perturbadas pelo episódio de Le Fever, em 1706. D epois de 1713, começam os amores com a viúva Wadman, que se encerram com a fuga para Shandy $\mathrm{H}$ all do herói, ofendido em seu pudor pela curiosidade indecente da 
viúva. Ele se refugia na casa do irmão na primavera de 1714. Informado do desenlace do "cerco", Walter deblatera contra as mulheres e 0 ato genital. $\mathrm{N}$ a mesma ocasião, o criado O badiah, que tinha engravidado sua mulher, queixa-se de que o touro, de propriedade de Walter, encarregado de cruzar com as vacas da aldeia, não tinha cumprido seu dever, deixando de emprenhar a vaca de 0 badiah. D esde então, os dois irmãos vivem juntos em Yorkshire. $\mathrm{N}$ a noite entre o primeiro domingo e a primeira segunda-feira de março de 1718, faz duas coisas rituais, dá corda na pêndula da sala e dorme com sua mulher, gerando Tristram. Este nasce no dia 5 de novembro de 1718. No dia 6, a criança é batizada com o nome indesejável de Tristram, no dia 7, ocorre a discussão entre os teólogos para decidir se era lícito rebatizar o menino. Entre 1719 e 1723, Walter redige um tratado sobre a educação de Tristram. Em 1723, o menino é circuncidado por acidente. Seguem-se as viagens à $\mathrm{F}$ rança e à I tália, até chegarmos ao presente, entre 1759 e 1766, em que Tristram escreve a história de sua vida e opiniões.

O ra, toda essa cronologia é sistematicamente distorcida pelo capricho do narrador. O tempo exterior só existe quando refratado na subjetividade de Tristram. Tudo se passa como se o narrador-personagem, depois de ter organizado sua obra segundo linhas cronológicas "normais", tivesse decidido embaralhála em seguida. Tristram se comporta como uma criança voluntariosa, que monta um quebra-cabeças e o desfaz com um gesto raivoso, dispersando todas as peças.

$M$ as Sterne não é Tristram. $N$ ada é menos infantil que seu método. Com enorme sofisticação, ele cria um tempo narrativo que remaneja o tempo da ação através de técnicas como a imobilização, a inversão, o retardamento e a aceleracão. São procedimentos absolutamente cinematográficos.

A imobilização corresponde ao desejo mais profundo de quem sofre com a contemplação da passagem inexorável do tempo. É o ver weiledoch, du A ugenblick, de G oethe, ou o $\mathrm{O}$ temps, suspend ton vol, de L amartine. Em Sterne, essa angústia se reflete no texto sob a forma tragicômica do que chamarei "efeito Bela Adormecida". É a câmara parando o fluxo do tempo, imobilizando imagens. U m personagem ou conjunto de personagens fica petrificado enquanto o narrador multiplica as digressões, até que o narrador o desperte, como o príncipe, no conto de Grimm, desperta o cozinheiro que durante cem anos ficara mumificado na atitude de esbofetear o ajudante.

0 exemplo clássico é a seqüência que se estende entre o capítulo 21 do livro I e o capítulo 6 do livro II. O uvindo um barulho no quarto da cunhada a ponto de dar à luz, o tio Toby diz: "I think...", e faz o gesto de sacudir as cinzas do cachimbo, apoiando-o na unha do polegar esquerdo. Ele fica imobilizado nessa posição durante quarenta páginas de digressões totalmente disparatadas. Concluídas as digressões, Toby se move de novo, jogando fora as cinzas, e dizendo o que pensava: que se tocasse a campanhia para mandar o criado chamar 0 médico ${ }^{11}$. M as há inúmeros outros exemplos. 
Tendo mencionado uma parteira, Tristram a esquece durante seis capítulos, e quando retorna ao tema manifesta algum remorso por um esquecimento tão prolongado. "It has been so long since the reader of this rhapsodical work has been parted from the midwife, that it is high time to mention her again" ${ }^{12}$.

Q uando Walter Shandy recebe a notícia de que o recém-nascido tivera 0 nariz achatado, o narrador deixa o pai prostrado na cama, num desespero extravagante. Sua posição não podia ser mais estranha. A palma da mão direita tocava a testa, o nariz repousava na colcha, o braço direito segurava a alça de um pinico, a perna esquerda estava dobrada, a direita pendia fora da cama, cuja beirada tocava a tíbia. Para explicar a aflição de Walter, Tristram o deixa nessa posição durante meia hora ${ }^{13}$. D ecidido a aproveitar esse tempo da melhor maneira possível, T ristram informa que a família Shandy sempre dera um alto valor aos narizes grandes, e que Walter tentara dar fundamento científico a essa convicção familiar, lendo todos os tratados que tinham sido escritos sobre os narizes. De repente, dá-se conta de que fora prolixo em excesso, pois já tinham se passado 35 minutos, e o pai continuava deitado na mesma posição ${ }^{14}$. Tristram prossegue, angustiado - tem tantas coisas a dizer, o tempo é tão curto - e acrescenta uma infinidade de digressões, entre as quais a história de um narigudo de Estrasburgo, dotado de um "nariz" cujo tamanho insólito encantava todas as mulheres. Finalmente, catorze capítulos e sessenta páginas adiante, Tristram consente em desfazer o feitiço, libertando Walter de sua catalepsia. 0 dedo grande do pé do enfeitiçado se mexe, para grande alívio do tio Toby, e Walter recupera sua mobilidade. Tinham se passado, não trinta minutos, mas uma hora e meia.

Em outra passagem, Walter é informado do falecimento do seu filho mais velho, e reage à notícia dissertando sobre a natureza da morte e recordando as circunstâncias da morte dos grandes homens, como o pretor Cornelius Gallus, que morrera fazendo amor. Espero que tenha sido com sua esposa, diz Toby. A mãe de Tristram ouve por uma fresta na porta a palavra "esposa" , e imagina que fosse ela o assunto da conversa. E m conseqüência, dispõe-se a escutar o diálogo, pondo o dedo entre os lábios, retendo a respiração e encostando o ouvido à fresta. "In this attitude", diz Tristram, "I am determined to let her stand for five minutes" 15 . Seguem-se várias páginas em outro cenário - a cozinha, onde Trim e outros criados discutem a morte do primogênito do casal, imitando à sua moda as dissertações filosóficas de Walter. Seis capítulos depois, Tristram se lembra, cheio de remorso, de ter esquecido sua mãe - "I am a Turk if I had not as much as forgot my mother, as if $\mathrm{N}$ ature had plaistered me up, and set me down naked upon the bank of the river $\mathrm{N}$ ile, without one"16. M as ainda não é tempo de descongelar a mãe. Ela fica paralisada na mesma posição, até que Walter, tendo passado da morte do pretor para a de Sócrates, lembra que em sua defesa 0 filósofo dissera: "eu tenho três filhos desolados". Só nesse momento a mãe se move, ainda sem saber da morte do filho, e supondo que Walter estivesse falando de si mesmo. Ela abre a porta e diz: nesse caso o Sr. tem um filho a mais do que 
eu sei. Ao contrário, responde Walter, tenho um a menos. É sua maneira de anunciar a M rs. Shandy que ela perdera um filho. Passaram-se oito capítulos, durante os quais ela ficara como uma estátua de pedra, o dedo nos lábios e os ouvidos colados à porta ${ }^{17}$.

Em certos trechos, o "efeito Bela Adormecida" se dá literalmente: os personagens adormecem de fato. D epois de tentar em vão explicar a Toby a natureza filosófica do tempo, segundo Locke, Walter fica exausto e cai no sono, sendo imitado por Toby. Tristram os deixa dormindo e aproveita para escrever seu prefácio. "All my heroes are off my hands; 'tis the first time I have had a moment to spare and I'll make use of it, and write my preface" ${ }^{18}$. Terminado o prefácio, Tristram desperta os dois irmãos por intermédio de uma porta mal-azeitada, que range quando Trim a abre ${ }^{19}$.

O utra técnica é a inversão, através da qual o narrador age sobre o flecha do tempo, corrigindo sua irreversibilidade. $\mathrm{H}$ á flash-backs, flash-for wards, e a interpenetração de ambos. 0 livro começa antes do começo e termina antes do fim. O começo, que deveria ser a história da vida de Walter e Toby, acaba sendo a história das calamidades pré-natais que perturbaram a concepção do herói e dos desastres que presidiram a seu nascimento. 0 fim, que deveria ser a maturidade do herói, no momento em que ele começa a escrever suas memórias, é o episódio final dos amores do tio Toby, isto é, quatro anos antes do nascimento de Tristram. No último volume, aparece o pastor Yorick, que toma parte na discussão sobre o touro impotente, enquanto o primeiro volume descrevera a morte desse mesmo pastor. Toby e Trim participam ativamente dos acontecimentos relacionados com o nascimento de Tristram, no início do livro, mas sua morte é descrita numa passagem consagrada a episódios que se passaram vários anos antes desse nascimento. No dia do parto, em 1718, aparece de repente um Tristram adulto, escrevendo suas memórias em 9 de março de 1759, isto é, com quase 41 anos. 0 mesmo Tristram adulto, contemporâneo do que escreve as memórias, ocupa o centro do Livro VII, fugindo a todo galope da morte, grande bloco narrativo que corta em dois a narrativa dos amores de Toby, ocorridos muito antes que o herói viesse ao mundo. Através da inversão, o passado pode tornar-se presente, ser retrouvé, no melhor sentido proustiano, e mesmo ser objeto de intervenção do narrador, como quando ele avisa o tio de que a viúva Wadman estava com más intenções ${ }^{20}$. E o futuro pode estar encrustado no passado: no meio das "campanhas" de Toby e de Trim, o narrador transporta a leitor a uma data que ainda estava muito longínqua, a morte desses dois personagens.

Em vez de imobilizar e inverter, a câmara shandiana pode também retardar a ação. Esse efeito de retardamento é obtido principalmente pelas digressões. D esde as primeiras páginas do livro, Tristram pede licença para contar a história à sua maneira, mesmo que isso significasse demorar-se na estrada, "trifling upon the road" 21 . 
M as assim como o narrador difere o progresso da ação, ele pode fazê-la avançar mais rapidamente. A câmara acelerada substitui a câmara lenta. São os dois extremos do método do narrador. Às vezes ele sente necessidade de contar todos os pormenores, de evitar qualquer empobrecimento do real, de captá-lo em toda sua riqueza de objetos e aspectos, em todos os reflexos que ele projeta na consciência do narrador e dos personagens. Por isso, ele não seleciona nada, não exclui nada, o que exige paradas freqüentes, desvios e retrocessos, para que tudo seja observado, registrado, inventariado. M as em outros momentos, 0 narrador se impacienta, convence-se da futilidade da descrição enciclopédica, do registro exaustivo, e a narrativa se torna rápida, alusiva, lacunar. 0 melhor exemplo é a própria autobiografia de Tristram. 0 narrador não explica nada sobre a vida do personagem, com exceção dos três ou quatro episódios de sua concepção, nascimento e maturidade. É que a câmara, aqui, optou pelo movimento rápido. As imagens desfilaram com tanta velocidade que o espectador só conseguiu captar uma ou outra cena, e acabou tendo que reconstituir o filme em sua imaginação. N um extremo, tudo é importante, e a câmara lenta se impõe, para que nada se perca; no outro extremo, nada vale a pena, ou pouco, e não há razão para evitar os hiatos e lacunas do texto, o que requer uma câmara altamente seletiva, em que as imagens se sucedem com a rapidez do relâmpago.

Esse tratamento arbitrário dispensado ao tempo da ação através das várias técnicas examinadas - imobilização, inversão, retardamento e aceleração - se reflete no caráter arbitrário das diferentes unidades lógicas - dedicatória, prefácio, capítulos.

N uma novela normal a dedicatória deveria servir de pórtico ao livro. Tristram faz a sua no final do capítulo 8 do livro I. Ele começa com uma invocação - M y Lord - deixando em branco o nome do personagem, e oferece a dedicatória, ao preço de cinqüenta guinéus, a qualquer duque, marquês, conde ou barão que deseje comprá-la, comprometendo-se, na segunda edição do livro, a preencher 0 espaço em branco com o nome do comprador ${ }^{22}$.

É óbvio, para qualquer autor não-shandiano, que um prefácio deve vir antes do texto. $\mathrm{N}$ ada de menos evidente para Tristram. É claro que também para ele o livro deve ter um começo, um meio e um fim, embora não necessariamente nessa ordem. 0 fim pode estar no começo, o começo no fim, e um e outro podem estar no meio. Se é assim, o que impediria um prefácio de vir no meio da novela, por exemplo, no capítulo 20 do Livro III? Conseqüentemente, é ali que Tristram põe seu prefácio, consagrado à tese de que o espírito (wit) e o julgamento não se excluem ${ }^{23}$.

E os capítulos? $\mathrm{N}$ ormalmente eles deveriam ser consecutivos - o segundo capítulo depois do primeiro, o terceiro depois do segundo etc. Para Tristram, isso é uma tirania insuportável. No último Livro, Tristram decide que precisa escrever o capítulo 25 antes dos capítulos 18 e 19, por mais que os críticos o censurem. Pois "how was it possible that they should foresee the necessity I was 
under of writing the $25^{\text {th }}$ chapter of my book before the $18^{\text {th }}$ etc.?" 24 . Em conseqüência, ele passa diretamente do capítulo 17 ao 20, e só muito mais tarde escreve os dois capítulos pulados, o que produz a seguinte série: $20,21,22,23,24$, $25,18,19 \ldots$ N ecessidade? D igamos necessidade shandiana. A inversão dos capítulos reflete a técnica da inversão que Sterne aplicou ao lidar com o tempo da ação, levando-o a terminar antes do começo.

A imobilização é o tempo zero da ação, o tempo sem tempo durante 0 qual não acontece nada, ou muito pouco. Ela se traduz visualmente em dois procedimentos típicos: a supressão dos capítulos e sua substituição por páginas em branco.

Tristram suprime de to do o capítulo 24 do Livro IV. Passamos do capítulo 23 diretamente ao 25, 0 que se reflete na numeração das páginas. $\mathrm{N}$ a edição Everyman, o leitor passa da página 312 à 323 . Tristram defende a supressão por razões estéticas. As páginas que faltam eram tão bem escritas, tão superiores ao resto do livro, que destruiriam o equilíbrio entre as diferentes partes da obra. $M$ as penso a verdadeira explicação é menos gratuita. No capítulo extinto, Tristram descreveria a viagem de Walter e seus companheiros a uma casa em que se realizaria uma reunião de teólogos, para discutir a questão gravíssima da possibilidade de mudar o prenome de Tristram, depois de efetuado o batismo. O ra, toda essa viagem foi feita sob o signo de mais uma excentricidade de Walter. Ela se realiza a cavalo, e não no coche da família Shandy, simplesmente porque as armas pintadas no veículo estavam heraldicamente incorretas, dando a impressão de que havia um ramo bastardo na família. Sterne não deixa dúvida sobre sua opinião a respeito: esse orgulho nobiliárquico era grotesco, e a questão era indigna de ocupar a atenção de pessoas sérias. "T is scarce credible that the mind of so wise a man as my father was, could be so much incommoded with so small a matter" 25 . 0 u seja, insignificante demais, a questão podia ser dada por inexistente, e o episódio da caval gada até a casa do teólogo, relacionada com essa não-questão, podia ser tratada num não-capítulo. Para todos os efeitos práticos, o tempo em que ela se realizou era um tempo vazio, exatamente como aqueles em que os personagens ficam imobilizados, aguardando o reinício da ação.

O utra maneira de refletir a imobilização é deixar capítulos em branco, como contrapartidas visuais dos tempos em branco. Essa técnica pode ser ilustrada pelos mesmos capítulos 18 e 19 com que ilustrei a técnica da inversão. Sterne não se limita a inverter a ordem, colocando esses capítulos dentro do capítulo 25, mas assinala graficamente os espaços vazios: depois do capítulo 17 vem uma página em branco, representando o capítulo 18, e uma página parcialmente em branco, terminando em uma partitura musical, que representa o capítulo 19. Sterne poderia ter facilmente invertido a ordem dos capítulos, sem ter deixado as páginas em branco. M as teria com isso omitido uma informação essencial, a de que os dois capítulos correspondiam na verdade a dois não-acontecimentos. N o capítulo 18, o tio Toby não fez nada para demonstrar o seu amor. Por inexperiência 
na arte de fazer a corte, ele se limita a dizer que estava enamorado, e senta-se no sofá, sem acrescentar nada. A viúva espera, em vão, que ele desenvolva o tema; mas o tempo passa, e Toby continua mudo e imóvel. 0 capítulo 19 descreve outra não-ação. Toby faz uma proposta de casamento, e mergulha ato contínuo na leitura da Bíblia, na parte mais apaixonante para seus interesses guerreiros - 0 cerco de J ericó. D e novo, ele não acrescenta nada.

When my uncle Toby had said this, he did not care to say it again; so casting his eye upon the Bible... he set himself to read it over - leaving his proposal of marriage, as he had done his declaration of love, to work with her after its own way. (662)

$\mathrm{N}$ os dois casos, estamos diante de um tio Toby que depois de ter dito coisas completamente insuficientes fica petrificado, seja na posição de uma estátua sentada, seja na de uma estátua lendo as Santas Escrituras. É verdade que esses dois tempos não são totalmente vazios. A pesar de tudo, Toby deflagra certas reações, dizendo no capítulo 18 que amava M rs. Wadman e no capítulo 19 que queria casar-se com ela. Por isso, os capítulos são suprimidos, porque desaparecem da seqüëncia normal, substituídos por espaços em branco, e não o são, porque reaparecem, misteriosamente, no interior do capítulo do capítulo 25. Com as páginas em branco, Tristram alude à pobreza dos conteúdos, mas reintroduzindo mais tarde os capítulos, ainda que invertidos, reconhece que eles não foram inteiramente nulos. Retirando esses capítulos de sua seqüência normal, Tristram obtém um poderoso efeito estético: cria, de saída, um contraste entre as expectativas amorosas de Toby ao entrar na casa da viúva, descritas no capítulo 17, e a decepção provocada pela curiosidade inconveniente da cortejada, descritas no capítulo que se segue imediatamente, o capítulo 20, cuja primeira frase alude ao desejo da viúva de ver o lugar onde Toby tinha sido ferido. Assim, a inversão desempenha o papel de criar uma relação imediata de contigüidade entre essas duas situações contrastantes, deslocando para depois os episódios intermediários, enquanto as páginas em branco têm a função de designar 0 vazio relativo dos acontecimentos incompletos.

Esses misteriosos capítulos em branco colaboram também para 0 atingimento de outro objetivo shandiano: o retardamento. 0 retardamento é obtido pela técnica da repetição. Assim, os capítulos 18 e 19 aparecem duas vezes, a primeira como espaço em branco e a segunda como texto. A repetição não está somente no fato de que as indicações "Capítulo 18" e "Capítulo 19" aparecem nas duas vezes, mas no fato de que o capítulo "pleno" se limita a duplicar o capítulo "vazio", que para um olhar atento não é tão vazio assim.

Assim, na versão "plena" do capítulo 18, a viúva Wadman fica olhando para um rasgão que ela estava cerzindo em seu avental, enquanto esperava em vão que 0 tio Toby acrescentasse alguma coisa às quatro palavras com que ele declarara seu amor. Em inglês, a frase é a seguinte: "M rs. Wadman naturally looked down, upon a slit she had been darning up in her apron, in expectation, 
every moment, that my uncle Toby would go on" ${ }^{26}$. O ra, se levarmos em conta que sit significa também fenda, cujo significado sexual é óbvio tanto em inglês como em português, não teríamos dificuldade em interpretar o gesto da viúva como uma ação sintomática no mais puro sentido freudiano: as palavras de Toby tinham dirigido os pensamentos da viúva para o ato genital. Para os que julgam excessiva essa interpretação, recomendo que meditem a seguinte passagem de Freud, a propósito, precisamente, de Tristram Shandy: "N a questão das ações sintomáticas, a observação psicanalítica deve ceder a prioridade aos escritores. 0 sr. Wilhelm Stross me chama atenção para a seguinte passagem no romance humorístico de Laurence Sterne, Tristram Shandy... " 27 Freud cita em seguida, em alemão, uma longa passagem de Tristram Shandy, que eu me permito abreviar e citar no original:

[... ] There are a thousand unnoticed openings, continued my father, which let a penetrating eye at once into a man's soul; and I maintain it, added he, that a man of sense does not lay down his hat in coming into a room - or take it up in going out of it, but something escapes, which discovers him ${ }^{28}$.

Por outro lado, o capítulo 19, em sua versão "plena" é uma preparação para a pergunta que se revelaria fatal para os projetos matrimoniais da viúva: ela queria saber o "lugar" em que Toby tinha sido ferido, pergunta que o inocente militar interpreta num sentido geográfico.

Assim, os dois capítulos contêm materiais sexualmente explosivos, apontando, respectivamente, para o pólo feminino e masculino da relação genital. É por isso que num primeiro momento eles são censurados, dissolvendo-se numa página em branco (versão "vazia") e só reaparecem num segundo momento (versão "plena") depois de parcial mente dissimulados pela descontextualização e pela inversão, que os retiram de sua seqüência natural. D esse modo, para um "penetrating eye", a versão "plena" é uma simples repetição da versão "vazia" . A mesma história é por assim dizer contada duas vezes, a primeira pelo silêncio e a segunda pela linguagem. A reiteração se põe a serviço do retardamento.

A extrema irregularidade no tamanho dos capítulos exprime 0 arbítrio do narrador no tratamento dos ritmos temporais. $\mathrm{H}$ á capítulos anormalmente longos e capítulos brevíssimos, que mostram a alternância entre a técnica do retardamento e a da aceleração. 0 tempo se arrasta, interminável (não é esse o sentido da palavra Langeweile, em alemão?) em capítulos como o 17 do Livro II, contendo o um sermão completo de Yorick, com mais de 20 páginas de texto ${ }^{29}$, ou no capítulo inicial, não-numerado, do Livro IV, com o conto atribuído a Slawkenbergius, o douto cronista dos narizes fálicos: nada menos que trinta páginas ${ }^{30}$. O s minutos se esticam, a câmara lenta explora tudo e não poupa nada. $\mathrm{N}$ o outro extremo, há inúmeros capítulos com menos de dez linhas e vários com pouco mais de duas linhas, como o capítulo 5 do Livro IV, em que Walter se irrita com Toby, dizendo que não é o momento de falar em pensões de granadeiros ${ }^{31}$, o capítulo 15 do Livro VI, em que Walter decide que digam o que 
disserem ele vai impor ao menino o uso das calças ${ }^{32}$, e o capítulo 9 do Livro IX, seguindo-se à invocação a J enny, na qual ele dissera: "H eaven have mercy upon us both". Esse capítulo consta unicamente das palavras: "N ow, for what the world thinks of that ejaculation - I would not give a groat" ${ }^{33}$. Esses capítulos minúsculos dão, evidentemente, a impressão de uma grande velocidade temporal. 0 contraponto entre capítulos tão longos que põem à prova a paciência do leitor e tão curtos que mal podemos sentir sua necessidade traduz com muita exatidão o modo astuciosamente ambivalente com que Sterne se relaciona com o tempo da ação, ora diferindo a narrativa com intercalações infinitas, ora se movendo com tanta rapidez que anos e mesmo décadas inteiras são telescopadas em poucos minutos de tempo narrativo.

A representação shandiana do espaço é tão caprichosa quanto a do tempo. Assim como o tempo do relógio, o espaço geométrico se desmaterializa, transformando-se em vivência subjetiva. O s personagens viajam, como observou M achado de Assis, mas o espaço que eles percorrem não se estende em linha reta de um ponto a outro, de uma a outra cidade. Este espaço previsível era o dos viajantes do Grand Tour, com um itinerário preciso, programado para que os jovens ingleses de classe alta pudessem completar e aprimorar sua educação. E ra também o espaço do Bildungsroman, como nos anos de peregrinação de Wilhelm $M$ eister, em que cada experiência encontrada no meio do caminho contribuía para a formação moral e intelectual do viajante. 0 espaço shandiano se parece mais com o do romance picaresco, como no Lazarillo deTormes, ou no Quixote. Sua lei é o acaso, a contingência dos encontros fortuitos, como no outro bestseller de Sterne, Sentimental J ourney, ou, pelo contrário, a N ecessidade, o D estino, a M orte, como no Livro VII de Tristran Shandy:

I will lead him a dance that he little thinks of - for I will galop, without looking once behind me, to the banks of the Garonne; and if I hear him clattering at my heels - I'll scamper away to mount Vesuvius - from thence to Joppa - and from Joppa to the world's end ${ }^{34}$.

0 viajante shandiano nunca visita o que interessa aos viajantes normais.

Em Sentimental Journey, o pastor Yorick diz que "I have not seen the Palais Royal - nor the L uxembourg - nor the façade of the Louvre - nor have attempted to swell the catalogues we have of pictures, statues and churches" ${ }^{35}$. $\dot{E}$ que o espaço é vivido e recordado de modo tão subjetivo quanto o tempo, ao sabor dos interesses e caprichos do viajante, de suas simpatias e antipatias - afinal, Yorick é um sentimental traveller, interessado em pessoas, e não em monumentos, movido por seus afetos e sentimentos, e não pela fria racionalidade de um guia turístico.

Se o viajante se comporta desse modo caprichoso, o narrador que relata essas viagens é igual mente caprichoso, só narrando o que interessa narrar. A qui 0 capricho assume a máscara da objetividade: se o historiador vai sempre em frente, desdenhando os caminhos laterais, está omitindo a descrição de regiões intei- 
ras da realidade. Para que o espaço real possa ser transposto sem falsificações no espaço narrativo, a totalidade desse espaço precisa entrar no texto.

Could a historiographer drive on his history, as a muleteer drives on his mule straight forward - for instance, from Rome all the way to Loreto, without ever turning his head aside either to the right hand or to the left - he might venture to foretell you to an hour when he should get to this journeys's end but the thing if morally impossible. For, if he is a man of the least spirit, he will have fifty deviations from a straight line to make with this or that party as he goes along, which he can no ways avoid. $\mathrm{H}$ e will have views and prospects to himself perpetually soliciting his eye, which he can no more help standing still to look at than he can fly; he will moreover have various accounts to reconcile, anecdotes to pick up, inscriptions to make out, stories to weave in, traditions to sift, personages go call upon... There are archives at every stage to be looked on, and rolls, records, documents, and endless genealogies ${ }^{36}$.

Como o espaço do narrador é sempre o espaço evocado, e nunca o que foi efetivamente percorrido pelo viajante, pode ocorrer que duas viagens feitas no mesmo espaço, mas em momentos diferentes, sejam vividas subjetivamente como simultâneas: o narrador-viajante faz as duas viagens ao mesmo tempo. Assim, ao narrar sua viagem como adulto à cidade de Auxerre, Tristram evoca sua viagem como adolescente à mesma cidade de Auxerre, em companhia de Walter e de Toby, o que leva Tristram a concluir, com sua peculiar lógica shandiana, que ele está fazendo ao mesmo tempo as duas viagens. "N ow this is the most puzzled skein of all...for I have been getting forward in two different journeys together, and with the same dash of the pen... I have brought myself into such a situation, as no traveller ever stood before me" ${ }^{37}$.

\section{Tempo e espaço em M emórias póstumas}

M achado de Assis leva à perfeição a característica shandiana de transformar o tempo objetivo num tempo subjetivo. I sso é coerente com a lei do capricho, que é o essencial da subjetividade shandiana: déspota em tudo, B rás $C$ ubas quer ser também senhor do tempo. M as Brás nãoné somente um tirano, é também um melancólico, e um dos traços fundamentais da sintomatologia melancólica é a angústia diante da transitoriedade das coisas. Seja como tirano, seja como melancólico, Brás quer a sensação de ter o tempo sob seu controle, e por isso o transforma em coisa sua. Para não estar sujeito ao tempo cronométrico, apropria-se dele como narrador e o maneja a seu bel-prazer. 0 tempo da ação subordina-se ao tempo narrativo.

O tempo da ação é de facílima reconstituição, porque como Tristram, B rás se esmera em balizá-lo com datas e fatos. 0 narrador nasceu no Rio de Janeiro, ainda no tempo de D. João VI, no dia 20 de outubro de 1805. Foi batizado em 1806. Desde os cinco anos era uma "menino diabo", quebrando a cabeça de escravas e cavalgando moleques domésticos. Em 1814, por ocasião da primeira queda de N apoleão, participou de um jantar de regozijo, e para vingar-se do D r. 
Vilaça, que o impedira de comer uma ambicionada compota, anunciou a todos que ele tinha dado um beijo em $D$. Eusébia, atrás da moita. Freqüenta uma escola, que o entedia e onde é condiscípulo de Q uincas Borba. Em 1822, ano da independência do Brasil, $B$ rás tem dezessete anos e inicia sua ligação com $M$ arcela. Ela 0 amou durante quinze meses e onze contos de réis, o que faz supor que a ligação terminou por volta de fevereiro de 1824. Embarca para a Europa, no navio de capitão poeta. Estuda em Coimbra e depois dos "anos da lei" bacharela-se, suponhamos que por volta de 1830. Passa alguns anos na Europa, o que nos leva, digamos, a 1834, quando volta ao Rio. M orre a mãe. Sobe para a Tijuca, e tem um breve namoro com "a flor da moita", Eugênia. Reencontra M arcela, desfigurada pelas bexigas. Conhece Virgília, que o pai Ihe reservara como noiva, mas a perde para L obo N eves. M orre o pai, humilhado com a desfeita sofrida pelo filho: um Cubas! Torna-se amante da ex-noiva. Encontra, transformado em mendigo, seu companheiro de escola, Q uincas Borba. Brás tem agora cerca de quarenta anos, e estamos em 1845. Aluga uma casa na Gamboa, com a cumplicidade de D. Plácida, para abrigar seus amores com Virgília. L obo N eves é nomeado para uma Presidência de província, e convida Brás para acompanhá-lo como secretário. $M$ as $L$ obo $N$ eves acaba recusando a nomeação, por medo do número treze. Brás acredita que vai ser pai, mas Virgília perde a criança. Lobo $\mathrm{N}$ eves chega de surpresa à casa da Gamboa, e quase pega os adúlteros em flagrante. Afinal é assinado novo decreto, com a data de 31, e V irgília parte para a província com o marido. B rás aceita com equanimidade essa partida, e janta bem no H otel Pharoux. Agora com quarenta e tantos anos, decide casar-se com N hãL oló, mas a moça morre de febre-amarela. Em 1855, aos cinqüenta anos, reencontra Virgília num baile. É eleito deputado, com ambições ministeriais, e estimulado por Q uincas Borba, faz um discurso propondo a diminuição da barretina da guarda nacional. M orrem D. Plácida, Lobo N eves, M arcela, e enfim Q uincas Borba, inteiramente louco. B rás tem a idéia de inventar um emplastro antimelancólico. E morre de pneumonia, aos 64 anos, às duas horas da tarde de uma sextafeira do mês de agosto de 1869.

Como tirano e melancólico, B rás C ubas sai dos seus cuidados para sabotar, na narrativa, a linearidade do tempo da ação, recorrendo a todas as estratégias de desorganização temporal adotadas por Tristram Shandy: a imobilização, a inversão, o retardamento e a aceleração.

I maginando um narrador morto, M achado de Assis ultrapassou de muito tudo o que Sterne inventou em matéria de imobilização do tempo. Tristram está continuamente ameaçado pela morte, fugindo dela em seu galo pe alucinado pela França, mas é quando estava vivo que ele escreve suas memórias. Ele pode sempre mudar suas opiniões, viver novas aventuras, encontrar outros personagens. Tristram é habitado pela permanente virtualidade da mudança. 0 narrador faz 0 que pode para criar para si mesmo a ilusão de controlar o tempo, mas sabe que faça o que fizer está sujeito às suas vicissitudes. E le está vivo, e portanto é mortal. 
$M$ achado vai incomensuravelmente mais longe em sua tentativa de exorcisar 0 tempo: ele se instala, como narrador, num tempo além do tempo, no tempo da eternidade. É um observador imóvel, protegido de qualquer mudança possível. Brás não podia emagrecer, porque as ossadas não emagrecem: "Restavam os ossos, que não emagrecem nunca" ${ }^{38}$. O leitor tinha "pressa em envelhecer" 39 defeito que não se podia atribuir a um autor defunto, que não envelhecia nunca. É o que Brás explica pacientemente a um crítico obtuso: “O que quero dizer não é que esteja agora mais vel ho que quando comecei o livro. A morte não envelhe$\mathrm{ce}^{\prime \prime}{ }^{40}$. Enfim, seus estados de espírito não mudam, pois ele está além da tristeza e da alegria: "Esta é a grande vantagem da morte, que se não deixa boca para rir, também não deixa olhos para chorar" ${ }^{41}$.

Esse narrador imóvel disserta sobre a contínua mobilidade de todas as coisas, o tempo que não cessa de fluir é observado sub speci ea eternitatis, e a morte é buscada como refúgio contra os terrores da morte. É um paradoxo que Freud compreenderia bem, pois para ele a pulsão da morte acaba coincidindo com E ros, já que em última análise a morte é repouso, fim do estado de tensão induzido pela incessante variação de to das as coisas.

A idéia do tempo imóvel faz seu aparecimento mesmo entre os vivos. $M$ as, nesse caso, é uma falsa imobilidade, uma imobilidade que não liberta.G eralmente, ela se manifesta, muito shandianamente, nas excentricidades gráficas, nos capítulos sem título, nos títulos sem texto. Por exemplo, o capítulo LIII, que narra o primeiro beijo de Brás Cubas e Virgília, não tem título. É que não é um verdadeiro capítulo, e sim um prólogo, o prólogo dos amores adúlteros que seriam narrados depois. "Tal foi o livro daquele prólogo." 42 Como prólogo, algo situado antes do início, corresponde a um tempo zero, um tempo imóvel antes que o verdadeiro tempo comece a fluir. Esse tempo imóvel é negativo, é o prólogo de uma vida de medo e hipocrisia, de cóleras, desesperos e ciúmes. O capítulo LV, "O velho diálogo de Adão e Eva", é construído sob a forma de uma peça de teatro, em que aparecem as dramatis personae - B rás C ubas e Virgília - mas em que as respectivas falas são substituídas por linhas pontilhadas, exclamações e interrogações. É a comédia universal dos sexos, comum a todas as épocas, além das variações da história, e nesse sentido o reino da intemporalidade, mas uma intemporalidade que nada tem de consoladora, porque é a condição para perpetuar "o legado de nossa miséria" . O capítulo CXXXIX, "D e como não fui ministro de Estado", também não tem texto: é que também alude a um tempo zero, um tempo vazio, o tempo imóvel de uma ambição frívola que não se realizou.

A inversão é outra estratégia shandiana usada por Brás Cubas. Ela permite ao narrador subverter a flecha do tempo, tornando-o reversível. Assim, o narrador volta atrás em capítulos já escritos, corrigindo-o num capítulo posterior, como faz quando decide intercalar o capítulo CXXX no capítulo CXXIX. M as o melhor exemplo de inversão temporal está no artifício central do livro, o processo pelo qual Brás Cubas decide começar suas memórias por sua morte, e não por seu 
nascimento. D uas razões o levaram a essa decisão, diz ele. Primeiro, ele não era um autor morto, e sim um morto que escrevia livros, e, portanto, podia fazer o que não pôde um Chateaubriand, por exemplo, no livro cujo título M achado de Assis parodiou, M émoires d'outre tombe. Segundo, o escrito ficaria mais novo, distinguindo-se nisso do Pentateuco, em que M oisés também conta sua morte, mas a põe no fim. É uma inversão mais radical que qualquer das inventadas por Sterne, mas que tem a sua lógica, uma lógica shandiana, bem entendido. Se a campa foi o segundo berço de B rás, ele nasceu no momento de sua morte, e com isso a cronologia "normal" se restaura, anulando a inversão. Essa idéia tem um ar curiosamente cristão, porque para certos pregadores sacros a verdadeira vida começa depois da morte.

O efeito de retardamento é obtido especialmente pelas digressões, tema que não posso tratar aqui. Lembro apenas uma grande seqüência cheia de digressões, uma das poucas que poderiam gerar al gum suspense no leitor - a entrada abrupta de Lobo N eves na casa de D. Plácida, com sua possível seqüela de cenas passionais e episódios de violência e até de assassinato. Esse episódio em que nada acontece se arrasta, interminável, ao longo de oito capítulos. N o capítulo CII, Brás anuncia que tinha praticado uma ação abominável. No capítulo CIII, revela que a ação abominável era que tinha se atrasado uma hora num encontro com V irgília, em casa de D. Plácida. N o próximo encontro, quando ele está conseguindo ser perdoado pela moça, D. Plácida anuncia que o marido enganado estava chegando. E le chega de fato no capítulo CIV, sem conseqüências particularmente trágicas, porque B rás não sai da al cova e Virgília explica que estava apenas visitando D. Plácida. N o capítulo CV , B rás aplica ao caso presente a lei da equivalência das janelas: seu gesto de querer sair da casa, enfrentando 0 marido e arrancando-Ihe V irgília, ação prudentemente impedida por D. Plácida, era uma forma de neutralizar a humilhação que ele sentira ao ficar escondido na alcova quando Lobo N eves chegara: a alcova fora uma janela fechada, e o gesto de sair, mesmo frustrado, uma janela aberta, destinada a ventilar a consciência. No capítulo CVI, D. Plácida se oferece para ir à casa de Virgília, a fim de verificar o que houvera entre o marido e a mulher. No capítulo CVII, há um bilhete de Virgília, dizendo que não tinha acontecido nada, mas que o marido suspeitava de alguma coisa. N o capítulo CVIII, B rás analisa suas emoções ao ler o bilhete. No capítulo $\mathrm{CIX}$, diz que releu o bilhete, antes e depois do almoço, e não se esquece de descrever o cardápio desse almoço, profundamente ascético, para desaprovação de Q uincas Borba.

O efeito de aceleração é também muito freqüente. O s anos de escola são mencionados em poucas linhas: "U namos agora os pés e demos um salto por cima da escola, a enfadonha escola, onde aprendi a ler, escrever, contar, dar cacholetas, apanhá-las, e ir fazer diabruras, ora nos morros, ora nas praias, onde quer que fosse propício a ociosos" ${ }^{33}$. C omeça a fal ar so bre seu colega de travessuras, Q uincas B orba, mas decide dar outro pulo: “Vamos de um salto a 1822, data 
da nossa independência política, e do meu primeiro cativeiro pessoal" ${ }^{44}$. C hamado de volta ao Brasil, Brás quer contar detal hes sobre sua volta, mas contém-se. É preciso ser rápido. "N ão alonguemos este capítulo. Às vezes, esqueço-me a escrever, e a pena vai comendo papel, com grave prejuízo meu, que sou autor." 45 $\mathrm{N}$ as cenas de luto, o tempo se abrevia, miniaturiza-se. Ao descrever a morte da mãe, o narrador faz questão de dizer que o capítulo era triste, mas curto. A morte do pai é descrita mais velozmente ainda, sob a forma de notas para um capítulo que não chegou a ser escrito ${ }^{46}$. 0 mesmo acontece com a morte de $\mathrm{N}$ hã-loló. Ela é anunciada num epitáfio, e comentada em poucas linhas, no início do capítulo seguinte.

0 epitáfio diz tudo. Vale mais do que se Ihes narrasse a moléstia de $\mathrm{N}$ hã-loló, a morte, o desespero da família, o enterro. Ficam sabendo que morreu; acrescentarei que foi por ocasião da primeira entrada da febre amarela. $N$ ão digo mais nada, a não ser que a acompanhei até o último jazigo, e me despedi triste, mas sem lágrimas ${ }^{47}$.

Seguindo a tradição shandiana, Brás C ubas percorre o espaço sem plano preconcebido, sem submetê-lo a categorias racionais. É o que acontece quando B rás caminha sem se dar conta disso em direção ao hotel Phraoux. Ele é conduzido pelas pernas, como um autômato, e não pela razão.

Enquanto eu pensava naquela gente, iam-me as pernas levando, ruas abaixo, de modo que insensivelmente me achei à porta do hotel Pharoux. D e costume jantava aí; mas não tendo deliberadamente andado, nenhum merecimento da ação me cabe, e sim às pernas, que a fizeram ${ }^{48}$.

$M$ as em geral os personagens shandianos se relacionam com o espaço através da viagem, e não através de perambulações automáticas, e Brás Cubas não é exceção alguma. $\mathrm{N}$ isso, $\mathrm{M}$ achado de Assis teve uma intuição certeira. $\mathrm{N}$ ão nos esqueçamos de que "toda essa gente viajou: Xavier de M aistre à roda do quarto, G arrett na terra dele, Sterne na terra dos outros. D e Brás C ubas se pode talvez dizer que viajou à roda da vida" ${ }^{49}$. M as pode-se viajar de dois modos, ou seguindo um guia Baedecker ou obedecendo a impulsos subjetivos. A viagem shandiana pertence à segunda categoria. Seu itinerário é guiado pelo capricho, pela volubilidade, ou pelo interesse sentimental. Foi o caso de Tristram Shandy, que não disse uma palavra sobre as atrações de Paris, ou Yorick, em Sentimental J ourney, que não quis saber do L ouvre, do Luxemburgo ou do Palais-Royal. D o mesmo modo, Brás Cubas resolve não dizer nada sobre o que viu na Europa, depois de bacharelar-se em Coimbra. Sabemos que percorreu a península, que esteve em outros lugares da velha Europa, onde assistiu às al voradas do romantismo, e que entre esses lugares estava Vezena, "ainda rescendente aos versos de lord Byron" ${ }^{50}$. E é tudo. "N ão direi coisa nenhuma. Teria de escrever um diário de viagem e não umas memórias, como estas são, nas quais só entra a substância da vida." ${ }^{51}$ I mpossível dizer mais claramente que o espaço só interessava na medida em que era evocado, e que só entraria na narrativa de modo impressionístico, arbitrário, determinado pelo processo associativo do narrador. 
É dessa natureza, em geral, o espaço que aparece em M emórias póstumas. Como o tempo, o espaço é desconstruído, transposto para dentro. 0 espaço se deforma na evocação e na narração. Torna-se subjetivo. 0 espaço urbano do Rio se atrofia, se desrealiza, reduzindo-se ao Rocio, onde Brás conheceu M arcela, à $T$ juca, onde ele se desfez da Flor da $\mathrm{M}$ oita, a rua dos $\mathrm{O}$ urives, onde ele reencontrou M arcela, à Gamboa, onde ele se encontrava com Virgília, e ao Catumbi, onde ele morreu. A distância entre dois pontos do espaço perde seu sentido topográfico, e transforma-se numa extensão abstrata cuja única função é ilustrar estados de alma do narrador ou aspectos de sua personalidade. Assim, a travessia marítima do Rio a L isboa se destina a ilustrar os sentimentos do narrador com a morte da mulher do capitão - poeta; seu percurso a lombo de jumento entre Coimbra e Lisboa a ilustrar sua mesquinharia; sua viagem da I tália ao Brasil a ilustrar sua tristeza com a morte iminente da mãe.

$M$ as que queria dizer $M$ achado de Assis quando afirmou que Brás Cubas tinha viajado em torno da vida? Sem dúvida, que seu personagem não tinha mergulhado na vida em si, caso em que teria ido além do seu desejo superficial de brilho, de vaidade, de prestígio, e tinha se limitado a viajar em torno dela, movido por seu ímpeto de "acotovelar os outros, de influir, de gozar... de prolongar a U niversidade pela vida afora" 52 . A expressão "em roda da vida" lembra a "imagem astronômica" que Brás desenvolveria no capítulo CL: "O homem executa à roda do grande mistério um movimento duplo de rotação e translação; tem seus dias desiguais como os de Júpiter, e deles compõe o seu ano mais ou menos longo" 53. O movimento de translação de Brás Cubas em torno da vida resultou num "ano" de pouco mais de sessenta anos, com "dias" inteiramente consagrados à frivolidade. A comparação astronômica sugere um movimento circular, de volta ao ponto de partida, o que significa que a "viagem" de Brás não o levara a lugar algum. Tinha se agitado muito, mas de fato não saíra do lugar. Com isso, o ideal shandiano do tempo imóvel acaba convergindo para o sonho da imobilidade espacial. Essa imobilidade, por razões diferentes, é a vocação mais íntima de todos os autores shandianos, por mais que viajem, o que só faz reforçar a filiação à forma shandiana de M achado de Assis, esse homem que nunca viajou.

N otas

1 M achado de Assis, "D om Casmurro", em O bra Completa, Rio de Janeiro, N ova Aguilar, vol. I, cap.1, p. 809.

2 L aurence Sterne, The Lifeand Opini on sof Tristram Shandy, N ew York, The M odern Library, s.d., livro IV, cap. 32, pp. 349-350. D oravante TS, seguido de algarismos que indicam o Livro, o capítulo e a página. [H á tradução para o português: A vida eas opiniões de Tristram Shandy, por J osé Paulo Paes (N ova Froneira, 1984). 
3 M achado de Assis, "M emóriaspóstumasde BrásC ubas", em Obra Completa, op. cit., vol. I, Prólogo da terceira edição, A o leitor e cap. 1, pp. 512-513. D oravante, M P e algarismos indicando o capítulo e a página.

4 J osé G uilherme M erquior, "G ênero e estilo nas memórias póstuma de Brás Cubas", C olóqui o/ Letras, Lisboa, jul. 1972, apud Enylton J osé de Sá R ego, “O calundu e a panacéia - M achado de Assis, a sátira menipéia e a tradição luciânica", Rio de J aneiro, Forense U niversitária, 1989, p. 198. Segundo M erquior, seriam as seguintes as principais características da sátira menipéia, todas direta ou indiretamente presentes em $M$ achado: 1) ausência de distanciamento com relação aos personagens e à ação; 2) a mistura do sério e do cômico; 3) liberdade do texto com relação aos ditames da verossimilhança; 4) a freqüente representação de estados psíquicos aberrantes; e 5) o uso constante de gêneros intercalados.

5 Como o foco deste artigo é a forma shandiana, não mencionarei as analogias de conteúdo entre Sterne e M achado de Assis, já amplamente documentadas por autores como Eugênio Gomes (Espelho contra espelho, São Paulo, Instituto Progresso Editorial, 1949) e Helen Caldwell (Machado de Assis, Berkeley, U niversity of California Press, 1970).

6 TS, II , 8, 104-105.

7 TS, I, 14, 37.

8 TS, IV, 13, 296.

9 TS, II , 8, 104-105.

10 TS, I, 4, 7.

11 TS, I, 21, 64; II , 6, 100.

12 TS, I, 13, 35.

13 TS, III, 30, 224.

14 TS, III, 38, 241.

15 TS, V, 5, 372.

16 TS, V, 11, 382.

17 TS, V, 13, 385.

18 TS, III , 20, 197.

19 TS, III, $21 \mathrm{~m} 209$.

20 TS, VIII, 24, 601.

$21 \mathrm{I}, 6,10-11$.

22 TS, I, 8, 15.

23 TS, III, 20, 197.

24 TS, IX, 25, 659.

25 TS, IV, 25, 324.

26 TS, IX, 25, 660.

27 Sigmund Freud, Zur Psychopathologie des A Iltags eben, "G esammelte Werke", vol. IV, pp. 237-238. 
28 TS, VI, 5, 430,

29 TS, II, 17, 123-145.

30 TS, IV, 251-281.

31 TS, IV, 5, 286.

32 TS, VI, 15, 452.

33 TS, IX, 9, 636.

34 TS, VII , 1, 496-497.

35 Laurence Sterne, A Sentimental J ourney, L ondon, Everyman's Library, 1947, p. 89.

36 TS, I, 14, 37.

37 TS, VII, 14, 534.

38 M P, XXIII, 545.

39 M P, LXXI, 583.

40 M P, CXXXVIII, 627.

41 M P, LXXI, 583.

42 M P, LIII, 569.

$43 \mathrm{MP}, \mathrm{XIII}, 531$.

$44 \mathrm{MP}, \mathrm{XIII}, 532$.

$45 \mathrm{MP}, \mathrm{XXII}, 544$.

$46 \mathrm{MP}, X L V, 562$.

$47 \mathrm{MP}, \mathrm{CXXVI}, 621$.

$48 \mathrm{MP}, \mathrm{LXVI}, 580$.

$49 \mathrm{MP}, 512$.

$50 \mathrm{MP}, X X I 1,544$.

51 M P, XXIII, 544.

$52 \mathrm{MP}, \mathrm{XX}, 542$.

$53 \mathrm{MP}, \mathrm{CL}, 634$.

Sergio Paulo R ouanet é diplomata. Foi E mbaixador do Brasil na D inamarca e em Praga. Escreveu, entre outras obras: I maginário e dominação (1978), H abermas (com Bárbara Freitag, 1980), Teoria crítica e psicicanálise (1983), A s razões do lluminismo (1987), Mal-estar na modernidade (1993), A razão nômade (1994) e Osdez amigosde Freud (2004). Traduziu A origem do drama barroco alemão, de Walter Benjamin. Pertence à Academia Brasileira de L etras.

Texto recebido e aceito para publicação em 19 de julho de 2004. 